\title{
Individualised cancer rehabilitation: developing a coordinated and comprehensive service model in a rural Australian hospital
}

\section{Background}

In 2016, Castlemaine Health established a cancer rehabilitation and survivorship service by re-orienting existing allied health and nursing resources into a cancer-specific stream within the outpatients service. The model of care sought to offer comprehensive, coordinated and tailored intervention to address the complex range of problems faced by cancer survivors; with additional pathways for older clients and their carers.

\section{Model of care}

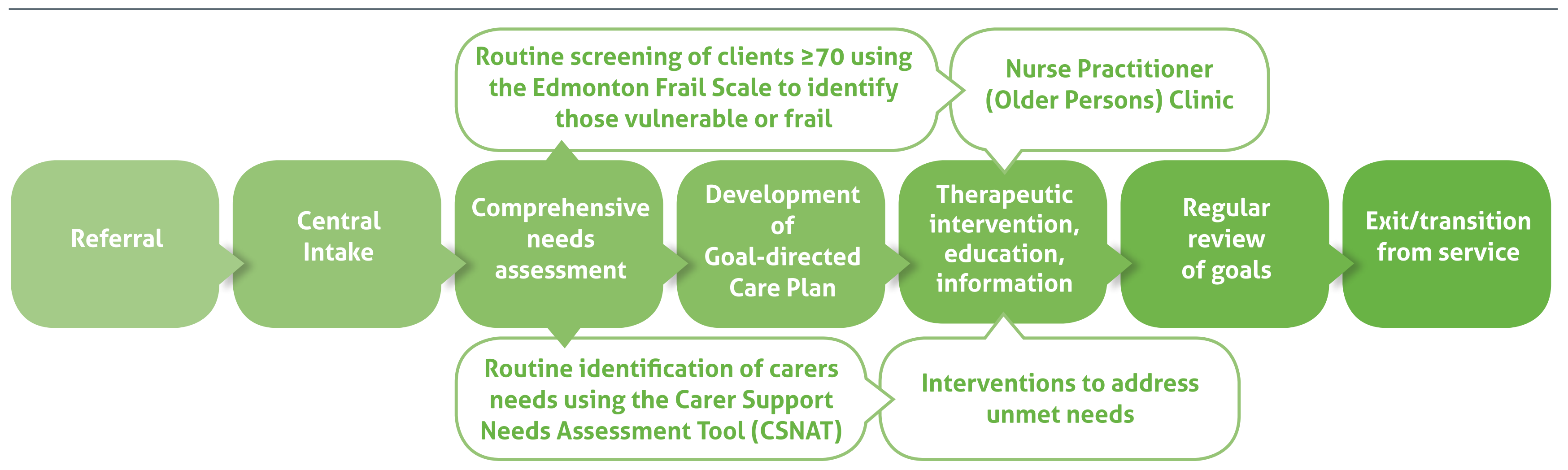

\section{Upskilled team}

$\begin{array}{lc}\text { - Physiotherapist** } & \text { - Social Worker } \\ \text { - Occupational } & \text { - Complex Care } \\ \text { Therapist* } & \text { Nurse } \\ \text { - Dietitian* } & - \text { Continence Nurse } \\ \text { - Speech } & - \text { Nurse Practitioner } \\ \text { Pathologist* } & \text { (Older Persons) } \\ \text { - Podiatrist } & \\ \text { "Most commonly utilised services }\end{array}$

\section{Carers}

- 15 (58\%) clients $\geq 70$ identified a carer

- Carers reported an average of 6 domains (out of a possible 14) in which they required further support (range 0-10).

\section{TOP 5 CSNAT RESPONSES}

\begin{tabular}{l|l}
\hline $\begin{array}{l}\text { Domain } \\
\text { dealing with your feelings } \\
\text { and worries }\end{array}$ & $8(73)$ \\
$\begin{array}{l}\text { talking with your relative about } \\
\text { his or her illness }\end{array}$ & $7(64)$ \\
$\begin{array}{l}\text { practical help in the home } \\
\text { knowing what to expect in the } \\
\text { future when caring for your } \\
\text { relative }\end{array}$ & $7(64)$ \\
$\begin{array}{l}\text { understanding your relative's } \\
\text { illness }\end{array}$ & $7(64)$ \\
\end{tabular}

\section{Client goals}

Individualised goal-directed care plans addressed a broad range of physical, emotional, social and practical needs.

The most frequently reported problems at baseline were fatigue (73\%), pain (49\%) nervousness (46\%) and poor memory/ concentration (46\%).

Clients set an average of four goals, with 76 percent of goals attained at discharge.

Example goals:

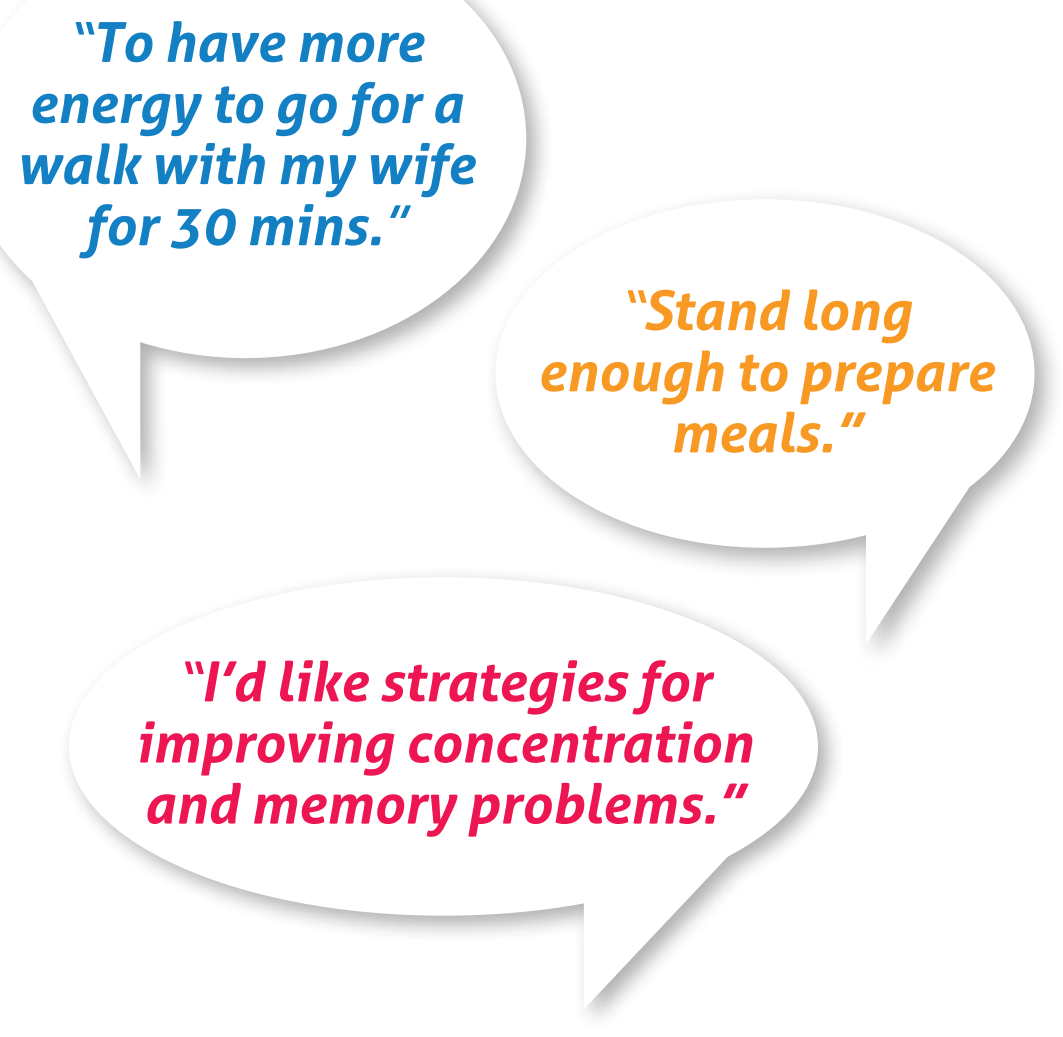

\section{Outcomes}

- Sustainable model of care

- Core team of clinicians with increased confidence in providing survivorship care

- Improved quality of life for local people affected by cancer

- Reduced burden of travel

- Adaptable model could be transferred to other community-based organisations

\section{CHANGE IN QUUALITY OF LIFE*:}

\section{T-score}

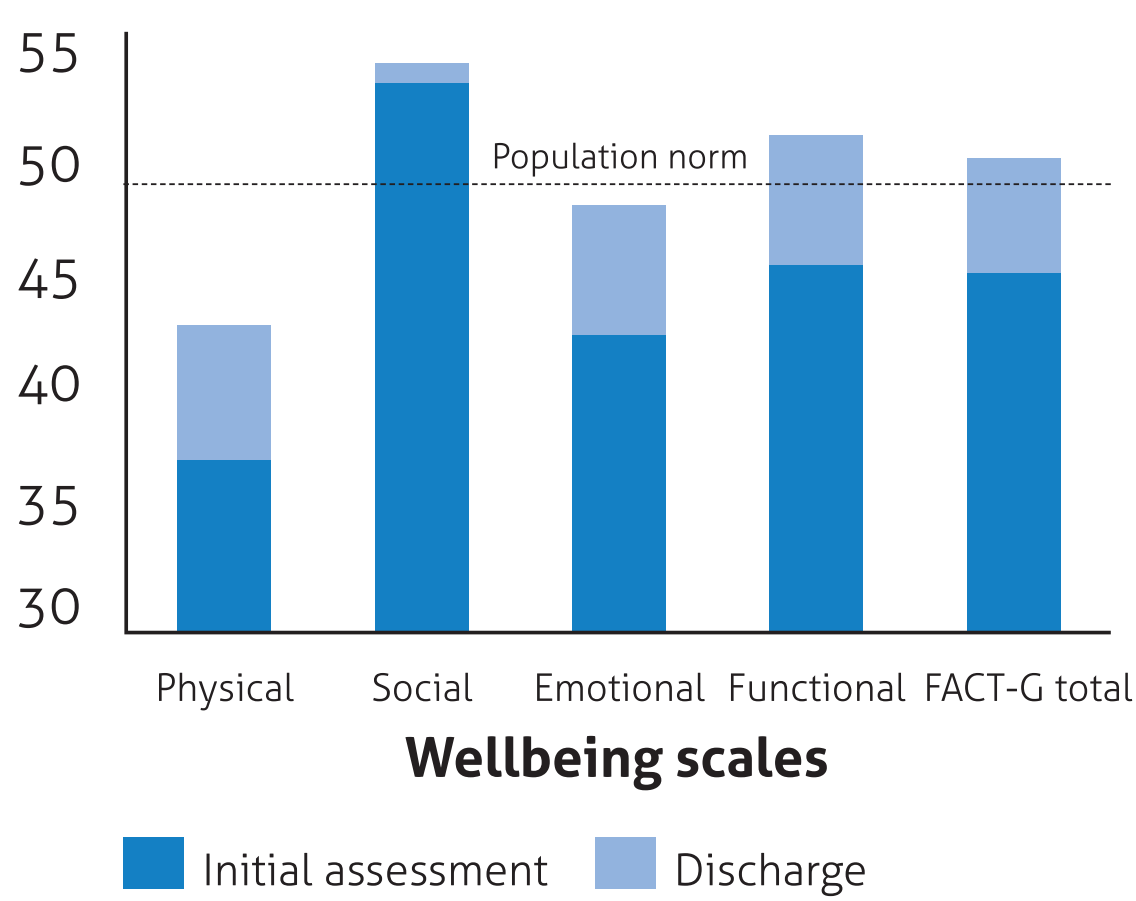

* Using the Functional Assessment of Cancer TherapyGeneral (FACT-G) 